\title{
Los talleres de poesía para niños con cáncer en Nicaragua: Una experiencia terapéutica y de animación a la lectoescritura'
}

\author{
Poetry Workshops for Children with Cancer in Nicaragua. \\ A Therapeutical and Promoting Literacy Experience \\ DANIEL RODRÍGUEZ MOYA \\ CoDirector del Festival Internacional de Poesía de Granada \\ España \\ danielrodriguezmoya@gmail.com
}

(Recibido: I7-O6-20I8; aceptado: 22-o6-2018)

La experiencia tallerista que el poeta Ernesto Cardenal puso en marcha durante la Revolución Sandinista (I979) y aún antes en la comunidad de Solentiname a finales de los años sesenta no acabó definitivamente con la abolición del Ministerio de Cultura ( ${ }^{9} 87$ ), del que él fue titular, y la posterior derrota del Frente Sandinista de Liberación Nacional en las elecciones de 1990. Como proyecto global sí acabó, pero la semilla de los talleres continuó, no solamente en Nicaragua. El propio Cardenal señala al respecto en una entrevista que "lo curioso es que después que estos talleres se acabaron influyeron en Estados Unidos, en un gran número de talleres para niños y jóvenes en diferentes lenguas y de varias etnias" (Rodríguez, 2009, p. 40).

En 2004, cuando de la revolución sandinista no quedaba ya ni las cenizas, Ernesto Cardenal se embarcó en un nuevo taller de poesía, pero esta vez no eran obreros y campesinos sus destinatarios, sino los pacientes del hospital infantil Manuel de Jesús Rivera 'La Mascota', en Managua. Un taller muy especial, que continúa en la actualidad en el que los participantes son niños con cáncer y leucemia.

La poesía, asegura el doctor italiano experto en oncología infantil Giuseppe Masera $^{2}$, es beneficiosa para las terapias de los pequeños.

Todos los martes del año Cardenal, junto a viejos conocidos como los poetas William Agudelo, Juan Ramón Falcón, Claribel Alegría, Luz Marina Acosta y alguno más, pusieron de nuevo en práctica aquellas las siete normas que popularizó para escribir poesía:

\footnotetext{
I Para citar este artículo: Rodríguez Moya, Daniel (2018). Los talleres de poesía para niños con cáncer en Nicaragua: una experiencia terapéutica y de animación a la lectoescrituras. Alabe 18. [www.revistaalabe.com] DOI: IO.I5645/Alabe20I8.I8.IO

${ }^{2}$ El propio Masera, conocedor de la experiencia de Cardenal en los talleres de Solentiname y en su etapa como ministro de Cultura fue el que le propuso hacerse cargo del taller de poesía del hospital Manuel de Jesús Rıvera 'La Mascota'.
} 
Allí se han producido muy bellos poemas, en los que se dice que las culebras ruedan por el suelo como alambres doblados; el colibrí mueve rápido sus alas como las aletas de un abanico; un ganso estira su cuello como un hule; la cola de la ardilla se enrolla como un caracol, y los monos caminan "parecido a los viejitos". Una niña dice que las caras de las ranas parecen gente fea cuando se están riendo, y un niño ve la bocota del sapo como la bocota de un señor gordo. En esta poesía las estrellas son “de color transparente”, la luna plateada como el agua, el sol tiene "pestañas rosadas" (Cardenal, 20o9, p. 236).

Esta experiencia tallerística que continuó semanalmente hasta mediados de 2015 hunde sus raíces en los primeros talleres de Solentiname y el posterior desarrollo de los talleres en todo el país tras el triunfo de la revolución y la puesta en marcha del Ministerio de Cultura con Ernesto Cardenal como responsable del mismo. Para entender esta iniciativa tenemos que remontarnos a los primeros momentos del triunfo revolucionario, con la puesta en marcha del hospital Manuel de Jesús Rivera 'La Mascota'3. El hospital, tal y como explica el pediatra y escritor Fernando Silva (entrevista personal) nace con la Revolución. Silva recibe el encargo de desarrollar este centro después de que hubiese ejercido su trabajo como médico en la montaña, en los días más duros de la lucha insurreccional. La puesta en marcha del hospital de manera completa se produce en I982. Silva ${ }^{4}$ señala que su primera sorpresa cuando se hace cargo del proyecto es que todos los expedientes que recibe con referencia a niños enfermos de leucemia tienen una cruz negra, es decir, que todos fallecen. La esperanza de vida de estos pequeños es prácticamente nula. Y es precisamente esa situación la que el empuja a trabajar por revertir esa terrible estadística:

Eso me da una preocupación no solamente en la mente, sino dolor en el alma. Un revolucionario que está movido por las necesidades del pueblo, por el interés de mejorar la vida siente eso horrible. Da la casualidad que en ese tiempo, aquí, en la revolución, habían venido todos los poetas del mundo, y en ese tiempo yo andaba muy cercano de Eduardo, que me quería muchísimo, fue mi hermano. Y entonces en base a eso, a esa situación horrible de tener los expedientes de los niños con leucemia, nació en mí el deseo infinito de crear algo en favor de los niños con leucemia y cáncer. (Silva, 20I4, entrevista personal)

\footnotetext{
${ }^{3}$ El hospital recibe el nombre de Manuel Jesús Rivera 'La Mascota' en honor de un niño que colaboró activamente con el Frente Sandinista de Liberación Nacional sirviendo de mensajero entre distintas células guerrilleras. A los trece años de edad fue asesinado por la Guardia Nacional somocista en la ciudad de Diriamba, el 5 de octubre de I978. Desde aquel mismo momento pasó a formar parte del extenso listado de nombres considerados por los sandinistas como mártires y héroes de la revolución.

${ }^{4}$ Entrevista personal realizada el II de julio de 20I4 en Managua, Nicaragua.
} 
No con pocas dificultades el doctor Fernando Silva comienza a sacar adelante el proyecto del hospital, para lo que cuenta con la inestimable ayuda del doctor Giuseppe Masera, un prestigioso oncólogo italiano del hospital San Gerardo de Monsa. En I986 funda, en el ámbito de este hospital un pabellón específico denominado pabellón de la Liga contra la Leucemia y el Cáncer en el Niño Julio Cortázar y comienza a trabajar centrando sus esfuerzos en este tipo de enfermos. La ayuda de Massera será fundamental para la puesta en marcha, dos décadas después de unos talleres de poesía en La Mascota dirigidos por el propio Cardenal:

"En un viaje que yo hice a Italia me visitó el doctor Masera, un gran especialista en niños y en la leucemia de los niños principalmente. Me dijo que los niños con leucemia solían desarrollar un talento muy especial para la narrativa, para la imaginación, para la expresión y creía que podían hacer poesía también, expresando con este talento que se les desarrolla, y me proponía que hiciera yo una prueba o un taller de poesía con estos niños. Me pareció muy buena la idea. Me lo proponía él porque yo había tenido mucha experiencia ya en talleres de poesía, no tanto de niños, pero sí en talleres. Así que valía la pena el experimento. Lo hicimos y desde el primer momento había muy buena poesía de estos niños (...) Una poesía buenísima y ha sido un gran éxito, aunque se presentó como un plan piloto para que se hiciera este mismo experimento en otros hospitales con otros niños, pero no se ha logrado aún. Aún sólo está el Hospital La Mascota de Managua”. (Entrevista personal)

El encuentro entre Masera y Cardenal es propiciado por Claudia Chamorro, hija del periodista Pedro Joaquín Chamorro, asesinado por sicarios del somocismo en I978, y de Violeta Barrios de Chamorro, expresidenta del Gobierno de Nicaragua (I99O-I997). Claudia había vivido en primera persona el drama de tener un hijo enfermo de leucemia y en el proceso de la enfermedad de su hijo conoció al doctor Masera, y en especial sus teorías acerca de los aspectos psicosociales para favorecer un entorno favorable en el tratamiento de la enfermedad:

"El profesor Masera, que como ustedes saben es el director del programa de oncología hematología pediátrica del instituto san Gerardo Monsa tiene particular interés en el área psicosocial con énfasis en el aspecto de la comunicación con los niños que están enfermos, es decir de los padres con los hijos, de los médicos con los hijos, de los cuidadores con los pacientes. Él tiene una gran admiración desde hace tiempo con Ernesto Cardenal, sabía el trabajo de Ernesto aquí en Nicaragua y conocía el vínculo familiar que yo tenía con Ernesto y me pidió a mí que hablara con Ernesto para servir de enlace para ver si estuviese interesado en extrapolar la experiencia que él había iniciado en la 
revolución para toda la gente y hacerlo para los niños con cáncer. Fui con el profesor Masera a donde Ernesto y Ernesto aceptó el reto que realmente encaraba dificultades porque tratándose de pacientes niños y con una enfermedad como el cáncer, que vienen de diferentes zonas del país iba a ser difícil garantizar el seguimiento, la atención permanente, unos niños no se sienten bien, otros se fueron porque no están y luego lo más triste, los niños que ya no pueden volver”. (2OI4 $)^{5}$

Los niños con leucemia, según le explica el propio Masera a Cardenal (Cardenal, 2009, p. 7) desarrollan una gran capacidad de expresión, por lo que considera que podría ser muy positivo llevar a cabo una experiencia que tendría dos puntos de interés, por un lado el estrictamente literario pero por otro uno de carácter terapéutico. La propuesta de Masera pretende servir como punto de partida para el desarrollo de más talleres en otros hospitales a lo largo del mundo.

Masera no escoge a Cardenal solamente por el hecho de la gran personalidad literaria que es, sino porque, como reconoce el propio autor nicaragüense, en sus numerosos viajes a Nicaragua para colaborar con el hospital Manuel de Jesús Rivera 'La Mascota' desde los aspectos más técnicos y financieros hasta los más estrictamente médicos, había conocido la experiencia que Cardenal desarrolló en el pasado al frente de los talleres de poesía.

Tras esta propuesta, que Cardenal acepta, tiene lugar un primer taller de poesía en La Mascota, taller al que asiste el propio Giuseppe Masera. Si en Cardenal se había dado alguna duda acerca de la idoneidad de hacerse cargo del proyecto, esta rápidamente se disipa cuando comienza a ver los primeros resultados, y es que, explica (Cardenal, 2009, p. 7) ya desde la primera sesión hubo algunos poemas interesantes de esos niños.

Transcurrido un año desde aquella primera sesión los talleres arrojan una gran cantidad de poemas muchos de los cuales poseen una calidad fuera de lo común, fuera de lo esperado. Cardenal compila todos aquellos trabajos que han ido elaborando los niños enfermos del hospital La Mascota y arma un libro, que lleva por título Sin arco iris fuera triste. Se trata de un volumen que reúne los mejores textos salidos de los talleres que fue ilustrado por Christa Unzner Koebel. Con posterioridad vio la luz un segundo libro, bajo el mismo concepto, que llevó por título Me gustan los poemas y me gusta la vida, un verso de uno de los poemas escrito por Ibis Palacios, una pequeña enferma de leucemia que falleció a los ocho años.

\footnotetext{
5 Entrevista personal realizada el 8 de julio de 20I4 en Managua, Nicaragua.

${ }^{6}$ Me gustan los poemas y me gusta la vida es también el título de una película documental de mi autoría rodada en el Hospital Manuel de Jesús Rivera La Mascota a partir de las entrevistas realizadas para esta tesis doctoral. La película se estrenó en España en abril de 20I5 y en Nicaragua en septiembre del mismo año. Traducida al inglés y al italiano, fue seleccionada en las secciones oficiales de importantes festivales internacionales de cine documental como el Al Jazeera International Documentary Film Festiyal

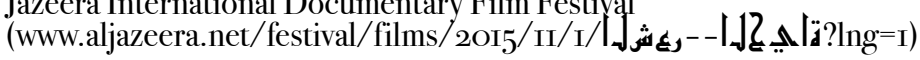


La puesta en marcha de este taller por parte de Ernesto Cardenal tiene sus peculiaridades respecto a los que ya había desarrollado con anterioridad, pero las líneas básicas serán las mismas. La experiencia adquirida tanto en Solentiname como durante los talleres populares por todo el país hace que el enfoque sea muy similar. "Por ser niños hay algo especial en ellos, que no hay en otros que ya son jóvenes o adultos, pero en todo lo demás es igual” asegura Cardenal (entrevista personal), que señala que a pesar de tratarse de niños enfermos "casi nunca hablan de su enfermedad si no que hablan de la vida":

"Una poesía que envidiaría cualquiera, que yo por ejemplo envidio. Como un niño que dice hablando de los gansos: el ganso que estira el pescuezo como un hule. Otro dice: las caras de las ranas parecen gente fea cuando se están riendo otro niño habla de las culebras que ruedan en el suelo y parecen alambres doblados. Otro dice que los venaditos, muy bonitos, con carita fina y nariz puntiaguda. Muy acertados ellos en sus expresiones. El colibrí, dice otro niño, moviendo sus alas con velocidad como las aletas de un abanico. Una niña habla de los periquitos, que cuando son chiquitos son peladitos como si le hubiesen puesto quimio. Otro niño dice la bocota del sapo que se parece a la bocota grande de un señor gordo. Otro habla el mono es negro con cara blanca y camina parecido a los viejitos. Una niña, Eleana, de diez años, el conejito es bonito, bonito como José Luis. Y otro niño dice que su chancho es gordo como don Chano Mundano. Increíble la capacidad de observación que tienen ellos. Unei, de io años, habla de los ojos del comején, de las terminas, que son amarillitas, dice. Otro niño hablas de los ojos de los hormigones que son redondos y rojos y otra niña describe un zancudo, es peludo y de color negro y de la boca es viejita.

Pues yo considero envidiable la poesía de estos niños aún para nosotros poetas ya viejos y ya profesionales. Y termino dando la definición de la poesía que un niño de 7 años, Michael Prat Pérez, tras una larga lista de palabras inconexas dice él, hormiga, hoja, libro, borrador, bolso, un montón de palabras más, y termina: todo es poesía. Lo envidiamos a todos estos niños". (Entrevista personal)

Para el desarrollo del taller en el hospital Cardenal recurre en una primera instancia a un viejo conocido, los libros que ya empleó en su día en Solentiname del poeta Kenneth Koch. Especialmente echa mano del titulado I Never Told Anybody, libro en el que el poeta norteamericano recoge su trabajo en un centro para mayores en la ciudad de Nueva York. Allí, recuerda Cardenal (Cardenal, 2009, p. 8) Koch llevó a cabo sus enseñanzas con personas mayores con enfermedades diversas a los que "enseñó a escribir buena poesía”. Además de este volumen, para los talleres del Hospital La Mascota Ernesto Cardenal recurre a otros dos títulos de Kenneth Koch ya analizados en este trabajo como son Rose, Where Did You Get That Red? y Whishes, Lies and Dreams. En esta línea Cardenal empleó técnicas que tanto a Kock como a él mismo le habían dado excelentes resultados como, el emplear poemas relacionados con animales: 
Uno de ellos era por ejemplo el mostrarles un poema dirigido a un animal, como el de William Blake a un tigre, y pedir que cada uno escriba cualquier otra cosa a otro animal. Otro recurso era poner un tema determinado, como por ejemplo el mar. Otro era decir a los alumnos que empezaran un poema con las palabras: Yo quisiera... o Yo recuerdo... o Yo soñé ... (segui segunda, como una contraposición, con la palabra Ahora. Para casos en que nadie pueda escribir nada, Koch propone que se haga un poema colectivo, cada uno escribiendo una línea distinta. (Cardenal, 2009, p. 8)

Cardenal consiguió nuevamente ejemplares de los libros de Kenneth Koch ya que los que utilizó años antes en Solentiname, los perdió cuando la Guardia Nacional somocista arrasó la comunidad (Cardenal, entrevista personal). Aunque estos recursos eran de gran utilidad y han demostrado su eficacia, Cardenal pronto se percató de que no eran estrictamente necesarios. Le sirvieron algo, de manera limitada, porque enseguida advirtió que era mejor no seguir ningún método, sino darles a leer los poemas que ellos mismos escribían el taller. Los niños prestaban mucha más atención cuando se leían sus propios poemas, "hemos visto que les interesa más la poesía de ellos mismos que leer a Neruda o a quien sea" (Cardenal, 20I4)?

En la misma línea que siempre ha adoptado Cardenal, a los niños participantes de los talleres del hospital La Mascota se le muestra que la poesía puede ser sin rima ni métrica, que puede tratar de cualquier cosa porque, "todo es poesía”, tal y como escribió un niño de siete años.

El modo de trabajar en este taller es muy sencillo y siempre suele ser el mismo. $\mathrm{Al}$ inicio de cada sesión ${ }^{8}$ se les explica (Cardenal, 2009, p.p. 8-9) que van a tener una clase para aprender a escribir poesía. Que escribir poesía es fácil, y que van a ver que ellos pueden hacerla. También que la poesía es algo divertido, como jugar, o como las adivinanzas. Que la poesía puede ser sobre cualquier cosa, y que pueden poner todo lo que se les ocurra. Cardenal insiste en este taller en explicarles a los pequeños que deben tratar de escribir una poesía que no tenga rima, volviendo a sus célebres siete reglas para escribir un poemas, algo que con el tiempo termina por no decir de manera obvia ya que con la simple muestra de los poemas que les muestran a los participantes ellos se percatan de esto. Por otro lado Cardenal también recalca a la hora de desarrollar el taller que "no tienen que preocuparse por la puntuación ni por la ortografía, porque no es importante en la poesía. Y que tampoco importa si no saben escribir, o no quieren hacerlo, porque pueden dictar el poema" (Cardenal, 20o9, p. 9).

\footnotetext{
${ }^{7}$ Entrevista personal realizada el iı de julio de 20I4 en Managua, Nicaragua.

${ }^{8}$ Cada sesión puede ser un comienzo del taller porque no siempre están los mismos niños. Los participantes, por las propias características de estos pequeños, varía mucho: "Desgraciadamente no les podemos dar seguimiento porque el taller es una vez a la semana, con los niños que hay en ese día, que han tenido cita por sus médicos, para ese día. Generalmente son distintos a los que estuvieron la vez pasada y entonces no podemos seguir con ellos, mejorar el poema... Lo tenemos que hacer allí mismo o ya no se hace”. (Cardenal, entrevista personal).
} 
El modo de proceder, después de que los niños hayan escrito sus poemas es invitarles a que los lean, aunque en muchas ocasiones es el propio Cardenal o alguno de los poetas que colaboran en el taller quienes los leen, ya que, considera el propio Cardenal "el autor suele gozar mucho cuando oye su poema en voz alta y con buena entonación" (Cardenal, 2009, p. 9).

El taller de poesía se realizaba de manera semanal, todos los martes, y solía tener una duración de dos horas, en las que al principio se les leía poemas para, posteriormente, pasar al proceso de escritura. Desde sus inicios Ernesto Cardenal no estuvo solo. Le han acompañado, entre otros poetas, dos viejos conocidos de la época de Solentiname como son William Agudelo y Marvin Ríos, además de la poeta Claribel Alegría, Daisy Zamora y, como responsable más activo en los últimos años, Juan Ramón Falcón, poeta que ya citamos en el capítulo correspondiente a los talleres de poesía del Ministerio de Cultura que pasó de ser uno de los participantes en los primeros encuentros a convertirse en monitor de talleres.

La temática de los poemas que surgen de estos talleres es muy variada y no necesariamente tiene que ver con la propia enfermedad que padecen los participantes:

Frecuentemente sus poemas son de añoranza de sus lugares. Lugares frecuentemente muy pobres, como aquel que un niño recuerda con los “árboles floreando", las carreteras descompuestas y los niños jugando. Y un niño de un pueblo enmontañado llamado Río Blanco, recuerda la belleza de las noches sin luz eléctrica en que la luna se pone más clara, hay muchas estrellas y el cielo es más bonito. Encuentro doloroso el poema del niño de io años que habla de lo alegre de su escuela y lo lindo de estudiar en ella, pero termina diciendo que cuando aprueban cuarto grado no pueden seguir estudiando en ella. Hay muchos poemas de niños miskitos de la costa del Caribe, con sus características muy graciosas, propias del lenguaje, a veces con palabras en su idioma, y poemas a veces completamente bilingües. (Cardenal, 2009, p. Iо)

Zamora (2OI4, entrevista personal), considera que la poesía les sirve para expresar lo que sienten y también lo que ven. Así, hacerlo a través de la poesía es mucho más importante que expresarlo con un dibujo. Zamora, en este sentido, destaca un poema que siempre le ha impactado. Es un poema de dos versos que dice: "No tengo nada / y nunca he tenido nada". En estas brevísimas palabra, entiende Zamora, se demuestra que los niños son capaces a veces de decir cosas de una profundidad impresionante, que no se puede conseguir a través de un dibujo.

Otra cosa que es importante para Zamora $(2014)^{9}$ es que los pequeños son muy observadores, la enfermedad o la cercanía de la muerte les hace ser niños que se fijan con especial atención en todo:

9 Entrevista personal realizada el II de julio de 20I4 en Managua, Nicaragua. 
Los niños de por sí los niños se fijan en todos los detalles, cuando uno es niño tiene como un microscopio en los ojos, que se van fijando en hormigas, en las hojas, pero además de eso ellos tienen como una agudeza especial para expresarse porque aparte de la capacidad de observación hacen una reflexión que por lo general tiene que ver con lo que ellos sienten que están marcados por algo y que la vida que tienen no es, no saben ellos cuánto les va a durar y eso los va a hacer ser mucho más reflexivos que un niño normal que puede ser observador, pero que está feliz y no piensa si quiera en la muerte, de pronto para ellos la muerte es una realidad y a veces hablan de la muerte con naturalidad porque claro ellos piensan que van a ir al cielo. (2014).

No son todos, pero de estos talleres han salido textos de una gran belleza y calidad literaria. Agudelo (2OI4) ${ }^{\mathrm{IO}}$, asegura que se han dado verdaderos hallazgos. Por ejemplo un niño de I 4 años llamado José Alejandro Martínez que escribió un poema que se llama La hoja casi en blanco:
No recuerdo nada
mi cerebro está vacío
los lugares se desaparecieron
de mi mente al igual que los colores.
Así dejaré la hoja
con pocas letras casi en blanco ${ }^{\mathrm{II}}$.

Agudelo (2OI4) se pregunta al respecto cómo un niño a tan tierna edad se puede ocupar de un problema que asalta más bien a escritores muy avezados, profesionales, y describe esa angustia de la hoja en blanco que no arroja nada, que no puede recibir ninguna palabra porque no se le ocurre.

La creación de imágenes sorprendentes e impactantes es un común denominador en los poemas que se crean en estos talleres. El propio Cardenal (2009, p. II) confiesa sentir envidia por esas imágenes que son capaces de crear:

(...) de un pollito persiguiendo un gusano que camina "estirándose y encogiéndose". O esa otra imagen de los gansos que con sus alas parecen un acordeón "que se abre y se cierra". Las culebras que rodando por el suelo "parecen alambres doblados". Las palomas blancas y café con blanco que salen de un árbol "como hojas que se elevan”. Los periquitos chiquitos que al decir de una niña estaban pelones como que les habían

\footnotetext{
Io Entrevista personal realizada el iı de julio de 20I4 en Managua, Nicaragua.

${ }^{\text {II }}$ Poema recogido en el volumen Me gustan los poemas y me gusta la vida.
} 
puesto “quicio”, El colibrí moviendo rápido sus alas “como las aletas de un abanico”. El ganso que "estira el pescuezo como un hule". La ardilla con la cola "enrollada como un caracol". Los monos que caminan "parecido a los viejitos". Y los venados con su carita fina y nariz puntiaguda, para quienes nosotros somos feos.

Es cierto, como decíamos anteriormente citando a Cardenal, que los niños participantes en el taller no suelen escribir demasiados poemas que tengan que ver con su enfermedad, aunque algunos sí que encontramos en el corpus que se recoge en las distintas antologías publicadas hasta el momento. En cualquier caso, los poemas sí que reflejan, siguiendo a Acosta (2OI4) $)^{\text {I2 }}$, "una radiografía social" ya que en ellos se puede apreciar las situaciones que viven estos niños con la pobreza casi siempre de fondo, el desarraigo familiar y demás condiciones que suelen ser denominador común de la mayoría de ellos. Y es que hay que tener en cuenta que en su mayoría, la procedencia de los niños enfermos de cáncer y leucemia ingresados en el Hospital La Mascota que participan en los talleres de poesía es de una extracción muy humilde, de zonas recónditas del país desde donde se tarda varios días a la capital, donde se encuentra ubicado el centro hospitalario. Así lo corrobora Lucía Paredes (2OI4) ${ }^{13}$, psicóloga del centro que habitualmente se entrevista con los pequeños para seguir su evolución:

Es muy útil porque generalmente se habla de las cosas que ellos están más necesitados de hablar, y eso nos ayuda mucho porque nos da un panorama de cómo están nuestros niños. Hay algunos que los vemos muy felices generalmente pero a la hora de escribir vemos algo que no estaba tan feliz como aparentemente lo podemos ver si solo nos lo quedamos viendo la carita. Tenemos niños que también muchos no hablan. Cuando vemos sus obras de sus lugares, cómo extrañan sus montañas, las cosas que comían, y es que uno no los ve a diario diciendo ahí yo quería comer los frijoles de mi casa, no te lo dicen así, pero cuando expresan, cuando crean, eso es lo que sacan. El amanecer de su valle, el río que corre cerca de su casa, el perro que dejó de ver.

\footnotetext{
I2 Entrevista personal realizada el II de julio de 20I4 en Managua, Nicaragua.
}

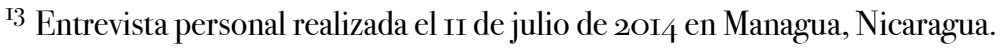


La experiencia del taller de poesía del hospital Manuel de Jesús Rivera 'La Mascota' como modelo en otras iniciativas internacionales: Sevilla (España) y Puebla de Zaragoza (México)

El taller que cada martes se llevaba a cabo en este hospital público de la capital de Nicaragua pudo saltar sus límites geográficos y sirvió como modelo y ejemplo para al menos dos iniciativas que tomaron el trabajo de Ernesto Cardenal como punto de partida para otros talleres de poesía en los que el objetivo es bastante similar. Nos referimos al taller de poesía que se puso en marcha en el Hospital de San Juan de Dios de la localidad sevillana de Bormujos, cuya primera edición se realizó entre mayo y junio de 20I6, y se dirigió esencialmente a pacientes con daños medulares, y por otro lado otro que se encuentra en fase de proyecto en un hospital de la localidad mexicana de Puebla de Zaragoza. Ambas iniciativas tienen como denominador común haberse realizado tras la visualización del documental Me gustan los poemas y me gusta la vida, una película de $5^{2}$ minutos de duración que realicé durante el proceso de investigación para la realización de esta tesis doctoral y en la que, como ya avancé, se contextualiza el taller de poesía para niños con cáncer que realiza Cardenal en el Hospital Manuel de Jesús Rivera dentro de los planteamientos tallerístico que inició Cardenal en Solentiname en los años sesenta.

Cada uno de estos talleres tiene sus características específicas en cualquier caso. La iniciativa del primer taller ya realizado partió de Alicia Martínez, miembro de un grupo poético denominado Generación Aljarafe, tras conocer el documental Me gustan los poemas y me gusta la vida. Los lesionados medulares del Hospital de San Juan de Dios del Aljarafe ha sido el espacio escogido para llevar a cabo la iniciativa a la que bautizaron como "Por prescripción poética". Alicia Martínez (20I6) ${ }^{\mathrm{I} 4}$ asegura que decidió, tras conocer la película Me gustan los poemas y me gusta la vida, desarrollar un taller similar con los pacientes con daños medulares porque "son personas a las que la vida se les ha truncado, no pueden caminar, todo cambia para ellos... ¿cómo aceptar algo así? Quizás sólo tomar conciencia de como se sienten les ayude. Cuando hay dolor uno casi que no quiere sentir. La poesía ayuda a eso, ayuda a todo" (Martínez, 2OI6). Rivero (20I6, s/p) señala a propósito de este taller que "el germen e inspiración del mismo es la experiencia que el poeta Daniel Rodríguez Moya tuvo con un taller similar en Nicaragua en el que participaban niños con cáncer. En este caso, se trata de pacientes con lesión medular y de sus acompañantes, quienes también sufren el enclaustramiento de la hospitalización” (Rivero, 20I6, s/p). La inspiración y modo de trabajar, por tanto, tiene mucho que ver con el modelo implantado por Cardenal en Nicaragua. Así, indica Rivero (2006), "las sesiones alternan los momentos de lectura y tertulia de poemas seleccionados por las tres poetisas implicadas, con otros en los que se recitan las piezas elaboradas por los alumnos y otros en los que se disfruta de la participación de un poeta invitado”. El taller se ha desarrollado a lo largo de seis sesiones ${ }^{15}$ de una hora y media de duración cada una de ellas

\footnotetext{
${ }^{\text {I4 }}$ Entrevista personal con Alicia Martínez realizada el I6 de junio de 20 o 6 en Bormujos, Sevilla.

I5 En los anexos de la tesis se puede consultar la secuenciación de las sesiones del taller.
} 
durante los martes, casualmente el mismo día en el que tiene lugar el taller nicaragüense, bajo la dirección de la poeta Sara Castelar, que ha sido la encargada de impartirlo junto a Alicia Martínez y Elena Marqués.

El documental Me gustan los poemas y me gusta la vida ha sido proyectado en diversos países como España, Nicaragua, Emiratos Árabes, Estados Unidos, Colombia y México. En el país azteca se estrenó en la ciudad de Puebla de Zaragoza el io de agosto de 2015 en el Instituto Municipal de Arte y Cultura. Entre los asistentes al estreno de la película se encontraba Aurora Bravo, escritora que colabora como voluntaria en el Hospital del Niño Poblano, que a partir del visionado de la misma comenzó a trabajar en el desarrollo de un proyecto para poner en marcha un taller de poesía similar en este centro hospitalario. La iniciativa aún no se ha materializado ya que forma parte de un programa pedagógico que deber ser aprobado por los órganos correspondientes del propio hospital, programa que actualmente se encuentra en fase de elaboración ya que, del mismo modo, forma parte de un protocolo de investigación para la obtención de la licenciatura en Lingüística y Literatura Hispánica ${ }^{16}$. Aurora Bravo explica de esta forma cómo decidió dar el paso para poner en marcha la iniciativa:

A partir del documental Me gustan los poemas y me gusta la vida, dirigido por Daniel Rodríguez Moya y Ulises Juárez Polanco, donde se lleva a cabo un taller de poesía para niños con cáncer, surge la idea de realizar un taller de creación literaria, en dicho documental se pueden observar a los poetas Ernesto Cardenal y Claribel Alegría, en el Hospital Infantil Manuel de Jesús Rivera 'La Mascota’ en Managua, Nicaragua, llevando poemas a los niños, los leen para ellos, platican y les piden que escriban un poema. De manera sorpresiva, la calidad de los poemas escritos por los pequeños, rebasó mis expectativas, en ese momento quedé agradecida por el panorama que se abrió ante mí mediante imágenes, a modo de altruismo y pasión. Por otro lado, la Dra. Pilar Carrasco Lluch, en 2008 realizó una tesis donde proponía que el modelo didáctico-terapéutico partiendo de la literatura infantil, en niños de 3 a I3 años ingresados en hospitales, puede atenuar sus estados de miedo y ansiedad; dicha tesis se llevó a cabo en el Hospital "Virgen de al Arrixaca" en Murcia, España. También, en octubre de 20I4, niños que ingresaron al Hospital Materno Infantil de Badajoz en España, participaron durante los meses de octubre y noviembre en un taller literario, puesto en marcha por la Consejería de Educación y Cultura, a través del plan de Fomento a la lectura en Extremadura, así como por el Centro de Estudios Literarios “Antonio Román Díez”. Notando así que la relación entre la literatura y niños hospitalizados, no es un tema nuevo. Este trabajo se

\footnotetext{
${ }^{16}$ El protocolo para el desarrollo de este taller en Puebla puede consultarse en los anexos de esta tesis.

${ }^{17}$ Protocolo de investigación de tesis para obtener el título de Licenciada en Lingüística y Literatura Hispánica. Aurora Marisol León Bravo.
} 
asemeja a la idea, pero buscando que los niños creen lo que más se les facilite, tal vez cuentos, tal vez poesía y utilizar estos medios como una terapia que reanime su situación. (Bravo, 20I6) ${ }^{17}$.

Además de estas iniciativas ya en proceso de desarrollo, estaba previsto que se ponga en marcha un taller similar en Bilbao, dentro del ámbito hospitalario, en tres centros sanitarios con chicas con anorexia, trastornos de personalidad y drogodependientes. 


\section{Bibliografía}

- Alegría, C. (20I4). Entrevista realizada el ir de julio de 20I4 en Managua (Nicaragua).

- Acosta, L.M. (20I4). Entrevista realizada el ir de julio de 2OI4 en Managua (Nicaragua).

- Agudelo, W. (20I4). Entrevista realizada el ir de julio de 20I4 en Managua (Nicaragua).

- Bravo, A. (20I6). Taller de lectura y creación literaria en el Hospital para el Niño Poblano. Puebla de Zaragoza: Benemérita Universidad Autónoma de Puebla. Facultad de Filosofía y Letras. Colegio de Lingüística y Literatura Hispánica.

- Cardenal, E. (2009). Me gustan los poemas, y me gusta la vida. Managua, Nicaragua: Anamá.

- Cardenal, E. Entrevista realizada el irde julio de 20I4 en Managua (Nicaragua).

- Paredes. L. (2OI4). Entrevista realizada el iı de julio de 20I4 en Managua (Nicaragua).

- Rodríguez Moya, D. (2009). Ernesto Cardenal: En Nicaragua tenemos una dictadura. Cuadernos Hispanoamericanos, 798, 37-48.

- Silva, F. Entrevista realizada el in de julio de 20I4 en Managua (Nicaragua).

- Villavicencio, A.P. (20I4). Entrevista realizada el 9 de julio de 20I4 en Managua (Nicaragua).

- Zamora, D. (20I4). Entrevista realizada el iı de julio de 20I4 en Managua (Nicaragua). 